\title{
Abstracts
}

\section{Community Health Care}

David Wilkin

\begin{abstract}
E. I. Williams, 'Characteristics of patients aged over 75 not seen during one year in general practice.' British Medical Journal, 288 ( I 984 ), I I $9-12 \mathrm{I}$.

L. Goldman, 'Characteristics of patients aged over 75 not seen during one year in general practice - correspondence.' British Medical Joumal, 288 ( 1984 ), 645.

N. J. Vetter, D. A. Jones and C. R. Victor, 'Effect of health visitors working with elderly patients in general practice: a randomised controlled trial.' British Medical Journal, 288 ( 1984 ), 369-372.

S. Ebrahim, R. Hedley and M. Sheldon, 'Low levels of ill health among elderly non-consulters in general practice. British Medical Joumal, 288 (1 984 ), 1 273 - 275.
\end{abstract}

In the two urban practices studied by Williams $93 \%$ of the population of over-75-year-olds had been seen by a doctor over a i 2-month period. The 44 patients not seen were visited in their own homes by a health visitor who completed a medical and social assessment. Although a majority were in good health, 31\% had impaired mobility, $14 \%$ had early dementia and $9 \%$ had urinary incontinence. The health visitor thought that just over half of the patients in the sample needed treatment. It is argued that the results demonstrate both the practicality and desirability of this type of 'case finding' or 'anticipatory care'.

In the correspondence generated by Williams' paper, Goldman reports a similar study carried out in Yorkshire. In this study $78 \%$ of patients born before 1900 had been seen by a doctor in the preceding I 2 months. Among those who had not been seen, $44 \%$ had no complaints about their health and most seemed remarkably fit and were not suffering unduly as a result of their lack of medical attention.

Patients over the age of 70 in two general practices (one urban, one rural) were randomly sampled by Vetter and his colleagues. Approximately $65^{\circ}$ in each area were interviewed and subsequently randomly allocated to intervention or control groups. The intervention groups were allocated to a part-time health visitor in each practice who made one unsolicited visit per year to each patient. Additional visits and/or referrals were made at the health visitor's discretion. Follow-up research 
interviews were conducted with both intervention and control groups after 2 years. There were no significant differences between intervention and control groups in physical disability, anxiety, depression, subjective view of life or social contact. However, in the urban area the intervention group received significantly more health and social services than the control group and, perhaps most surprisingly, experienced significantly lower mortality. This pattern did not apply to the rural area. The authors conclude that there is evidence from the study that the provision of a health visitor in an urban general practice reduced mortality and increases the provision of services. They suggest a need for more research to determine why the same pattern was not found in a rural area.

In the last of these papers, the elderly patients in a group practice were divided into those who had seen their GP in the preceding 18 months and those who had not. The authors set out to compare consulters and non-consulters in terms of their health problems, functional capacity and use of services. They demonstrate the practicality of using a postal questionnaire to conduct this sort of case finding exercise. The results show the non-consulters to be a low risk group, in good health and using few services. In contrast, consulters were much more likely to suffer functional restrictions and to report a variety of health problems. Differences between consulters and non-consulters were most pronounced for the $75+$ age group. Thus $32 \%$ of consulters in this age group were unable to go outdoors alone compared with only $6 \%$ of non-consulters. Greater functional impairment was reflected in greater service contact so that $22 \%$ of consulters aged $75+$ had received hospital inpatient treatment in the past year compared with $3 \%$ of non-consulters. The authors recommend that the GP's attention be focused on the consulters and that postal questionnaires be utilised as a method of case finding among non-consulters.

\section{COMMENT}

There are methodological problems with each of these studies, but these are less important than the substantive issues raised by the various forms of 'screening', 'case finding', anticipatory care' 'surveillance', etc. employed. None of the articles even suggests that there might be a problem of legitimacy in the use of such procedures. The routine surveillance of elderly people who have not sought care from the health services is rapidly becoming an accepted part of primary health care. Indeed it comes to be expected of the professions responsible for providing health care in the community. Thus there is an outcry when an old person dies at home unknown to the services. But the alternative 
of regular surveillance carries with it other dangers. It challenges the individual's right to privacy and to choose when and when not to seek the help of services. In many instances the professionals, having identified a problem, will be unable to help either because of a lack of resources or an absence of technical solutions. In such situations it might be considered irresponsible to actively seek out the problems only to inform patients that nothing can be done. These issues should be given serious consideration. The pages of the British Medical Journal might be a suitable place to begin a debate, provided that they can incorporate the views of older people as well as the views of their doctors.

Apart from their failure to address the ethical issues involved, these papers illustrate the need for much more research which examines the effectiveness and efficiency of health care. It is all very well to describe methods of case finding, but we need to know whether such approaches are an effective and efficient way of improving the health of old people. Only the article by Vetter and his colleagues directly addresses the problem of effectiveness, and this with somewhat equivocal results. In the present economic climate, schemes which simply demonstrate an ability to uncover needs without considering how these needs are to be met are unlikely to prove very popular with policy makers.

C. J. Gilleard, E. Gilleard, K. Gledhill and J. Whittick, 'Caring for the elderly mentally infirm at home: a survey of the supporters.' Journal of Epidemiology and Community Health, 38 (1984), 319-325.

This study of I 29 supporters caring for mentally infirm old people at home confirms a now familiar pattern in which informal care is largely the province of wives and daughters and support from services is at best sparse. The elderly mentally infirm had all been referred to a psychogeriatic day care service. A variety of psychometric scales was used to assess strain, burden and social interaction between supporter and dependent. A problem checklist provided information about the presence of 28 possible problem behaviours that could be exhibited. Detailed information was collected on domestic circumstances, service support and informal help.

Only 27 of the I 29 supporters were men and most supporters received little help from services. Less than a quarter received regular visits from the district nurse, one third received home help and less than $10 \%$ meals on wheels. The paper provides much detailed information about service contacts and the prevalence of problem behaviours. Age of the carer is shown to be an important factor predicting burden and strain. Older 
supporters generally experienced less strain than younger ones, and those who lived with the elderly person experienced more strain than those who lived apart. However, the principal determinant of burden and strain was simply the number of problem behaviours. The range of formal and informal support available to the supporters played no significant part in the variations in the degree of stress reported.

\section{COMMENT}

This paper is a very useful addition to the gradually accumulating body of research on carers. It provides much needed information based on a substantial sample of carers. However, some of the analyses might be considered somewhat naive. Thus the division of carers into young and old (less than 65 years and 65 plus years) is a very crude means of describing complex inter-generational relationships. It might be more fruitful to explore in more depth some of the wealth of information available, rather than limiting analyses to those variables which generate sufficiently large cells to permit statistical tests.

By far the most important finding is the reported absence of a relationship between service provision, strains and burden. If this is true it should lead to some fundamental questioning of the assumptions underlying the provision of services for the elderly. However, it would be wise to sound a note of caution. The authors point out earlier in the article that the level of services provided was low. It may not be surprising to discover that variations in a low level of provision have less impact on strain and burden than the frequency with which problems occur. This does not necessarily mean that all services are irrelevant to the burden on carers. Indeed the penultimate sentence of the paper reports that $76 \%$ of supporters felt they could go on caring with the help of the day hospital, presumably implying that at least this service played an important part in their perceived ability to cope. It would certainly be unfortunate if the conclusion of this paper were used to justify a failure to provide services to meet the needs of those supporting the elderly in the community.

The Department of General Practice, University of Manchester. 